\title{
Role of emotional stress in the pathophysiology of Graves' disease
}

\author{
Géraldine Falgarone ${ }^{1,2}$, Hassan M Heshmati ${ }^{3}$, Régis Cohen $^{4}$ and Gérard Reach ${ }^{4}$ \\ ${ }^{1}$ AP-HP, Service de Rhumatologie, Avicenne Hospital, Hôpitaux Universitaires Paris-Seine Saint-Denis, 125 Route de Stalingrad, 93009 Bobigny Cedex, \\ France, ${ }^{2}$ Sorbonne Paris Cité, Université Paris 13, EA 4222, Li2P, 93009 Bobigny Cedex, France, ${ }^{3}$ Gelesis, Inc., 1764 West Dion Drive, Anthem, Arizona \\ 85086, USA and ${ }^{4}$ AP-HP, Service d'Endocrinologie, Diabétologie et Maladies Métaboliques, Avicenne Hospital, Hôpitaux Universitaires Paris-Seine \\ Saint-Denis, 125 Route de Stalingrad, 93009 Bobigny Cedex, France \\ (Correspondence should be addressed to G Reach; Email: gerard.reach@avc.aphp.fr)
}

\begin{abstract}
The role of stress in the pathophysiology of Graves' disease is suggested by several clinical observations, by recent advances in immunology and by better understanding of autoimmune diseases which provides new insights into potential effects of stress hormones on T helper cell imbalance involved in the pathogenesis of autoimmune diseases. Stress management should therefore be an important part of the treatment of Graves' disease, as stress reduction may improve the effect of therapy. However, this field still requires interventional data to support stress management in the treatment of Graves' disease.
\end{abstract}

European Journal of Endocrinology 168 R13-R18

\section{Introduction}

The association of goiter and orbitopathy was first described between AD 1000 and 1110 by two Persian physicians and philosophers, Avicenna and Al-Jurjani (1). In 1825, several years before the description of Graves' disease by Graves (2) and Basedow (3), Parry described the case of a 21-year-old woman who fell out of a wheelchair while going fast down a hill (4). She was extremely frightened without being badly hurt. Shortly after that event, she developed nervousness, palpitations, and swelling of the thyroid gland.

It took some time to understand the pathophysiology of Graves' disease. Initially, it was considered a disease of cardiac (according to Parry and Graves), nervous (according to Charcot and Pierre Marie who described the tremor), or thyroid (thyroid surgery started in the 1880s) origin. Later, following the discovery of thyroid stimulating hormone (TSH) in 1933, Collip suggested that it was a disease of pituitary origin. In the late 1950s, Adams and McKenzie discovered in the serum of the affected individuals a long-acting substance stimulating the secretion of thyroid hormones. In 1965, this substance called long-acting thyroid stimulator was characterized as being an antibody against a thyroid component (5). In 1978, this thyroid component was identified as the TSH receptor (RTSH) (6).

In general practice, clinicians are often convinced about the role of stress not only in triggering the disease but also in the effectiveness of the treatment (i.e. rest, use of beta blockers or benzodiazepines).
The objective of this article is to describe evidence of the involvement of stress in the pathophysiology of Graves' disease based on an extensive review of the literature. We think that it is possible to have a plausible mechanism for the role of stress based on recent advances in immunology.

\section{Epidemiological data on stress and Graves' disease}

The role of stress in the pathophysiology of Graves' disease was proposed very early, especially during the Boer War and the First World War. Some of the publications reported the presence of stress in 62 or $85 \%$ of the cases, or even in all cases (review in (7)). A review of the literature including seven case-control studies has highlighted the preexistence of a 'negative' stressful event in patients with Graves' disease (8, 9, 10, $11,12,13,14,15)$. However, one can criticize the principle of case-control studies: it is difficult to assess the effect of a given stressful event in different individuals; the validity of filling out a questionnaire may be limited in an emotional context, the actual date of the onset of the disease is difficult to specify and nothing proves that it occurred after the stressful event (8). However, a prospective study conducted in Serbia shows that while the incidence of Graves' disease had been stable since 1971, it increased significantly between 1992 and 1995, i.e. during the war (16). Despite these criticisms, we can consider that the effect 
of stress on the onset of Graves' disease is at least possible. Therefore, it is necessary to consider if we can propose a plausible mechanism.

\section{Plausible pathophysiological mechanisms for the effect of stress in Graves' disease}

\section{Genes and environment}

Although Graves' disease has a well-known familial tendency, heredity does not explain everything $(17,18$, 19). A study of twins, who are not always 'concordant' for the disease, suggests that genetic factors explain $79 \%$ of the incidence of the disease, while environmental factors are responsible for $21 \%$ of the cases (20). A recent study shows that the risk of having Graves' disease is multiplied by 5 if there is one affected member in the family, by 310 if there are two affected members in the family, and by 16 if one twin is affected. The risk is higher in men than in women. The finding that the risk is increased among spouses by 2.75 highlights the role of the environment (21). The environmental parameters commonly reported as contributing factors are infectious agents, iodine, drugs (amiodarone, interferon- $\alpha$ (IFN- $\alpha$ ), and CD52 MABs), tobacco, and stress (22).

\section{Autoimmunity}

Hashimoto's thyroiditis was previously considered a predominantly T helper 1 (Th1) autoimmune disease. The lymphocytic infiltrate contains B cells and T cells (with a predominance of Th1 or Th17 subtype). The disease is manifested by the presence of anti-thyroid peroxidase and anti-thyroglobulin antibodies following the apoptosis of the thyroid follicular cells induced by the immune cells. This cell destruction leads to hypothyroidism. Graves' disease is still considered a predominantly Th2 autoimmune disease. The lymphocytic infiltrate contains Th2 lymphocytes. The disease can result in the production of stimulating anti-TSH receptor antibodies causing goiter and hyperthyroidism. In $50 \%$ of the cases, the antibodies are blocking the TSH receptor and cause thyroid atrophy and hypothyroidism (23). Finally, a recent publication provided the evidence for a high Th1/Th2 cell ratio in patients with clinical Hashimoto's hypothyroidism, and a high proportion of Th17 cells in intractable Graves' disease (24).

To better understand how stress may affect the development of a thyroid autoimmune disease, it is necessary to remind that this pathology displays a tolerance disruption and that the antibodies against TSH receptor are Th cell dependent. While Graves' disease was considered for some time as an only Th2 disease, it is now admitted that autoantibodies against TSH receptor could also be Th1-dependent antibodies.
Indeed, the same antigen (TSH receptor) can trigger both types of Th differentiation (Th1 or Th2) depending on the way of processing the antigen by the antigenpresenting cells (APCs), which is directly related to the route of injection or transfection in APC. Thus, the Th2 immune response seems to be predominantly involved in mouse models using APC (fibroblasts or B cells) expressing the TSH receptor in a major histocompatibility complex (MHC) type II molecules context, while Th1 cells are key cells in models where immunization is obtained with plasmid or adenovirus-transfected cells as well as dendritic cells (DCs) expressing the TSH receptor (25). The first case involves the extracellular trafficking of the antigen into APC leading to MHC class II presentation while the second case is more like an endogenous presentation of the antigen leading to a MHC class I presentation (Fig. 1).

Th17 cells are CD4 T effector cells described more recently, producing interleukin 17 (IL17) and implicated in the pathophysiology of many autoimmune diseases. The contribution of IL17 has been clearly demonstrated in a model of IL17-deficient mice. However, the genetic context is critical: surprisingly, the commonly Graves' disease-susceptible BalbC strain is not Th17 dependent. In contrast, the non-susceptible non-obese diabetic (NOD)-H2 ${ }^{\mathrm{h} 4}$ mouse model is IL17 dependent. While demonstrating the implication of IL17 and Th17 effector cells, these data show the implication of IL17 regarding the genetic context in mice models (26).

The complexity of the Th1/Th2/Th17 imbalance has been demonstrated in the thyroiditis mouse model. Indeed, Horie et al. (27) showed that both Th1 and Th2 cells are critical for the development of the iodineinduced autoimmune thyroiditis in NOD mice. Furthermore, Th17 cells have been implicated in the human Hashimoto's disease (28). In parallel, it has been demonstrated that impaired regulatory functions can be observed in patients with Graves' disease. In the mouse model, regulatory $\mathrm{T}$ (Treg) depletion renders C57BL/ 6 mice susceptible to induction of Graves' disease (29). Indeed, Treg cells CD ${ }^{+} \mathrm{CD} 25^{+}$Foxp $3^{+}$ displaying a regulatory phenotype have been found to be low in untreated Graves' disease patients and inversely correlated with serum concentration of TSH receptor antibodies. Recently, Hu et al. (30) confirmed the role of Treg in Graves' disease. They observed that intrathyroid injection of dexamethasone increased Treg function while it has no effect on Treg proportion in peripheral blood cell count or on Foxp3 RNA expression. In parallel, when investigating the maturation and phenotypes of DC, Mao et al. (31) observed that plasmacytoid DCs (pDCs) were numerous and produced IFN- $\alpha$. They showed that these pDCs were able to induce apoptosis in Treg cells. The inhibition of production of IFN- $\alpha$ with a nucleotide blocking the P2Y6 receptor signaling (expressed on both DC and macrophages) modified pDC and restored suppressive function of Treg. 


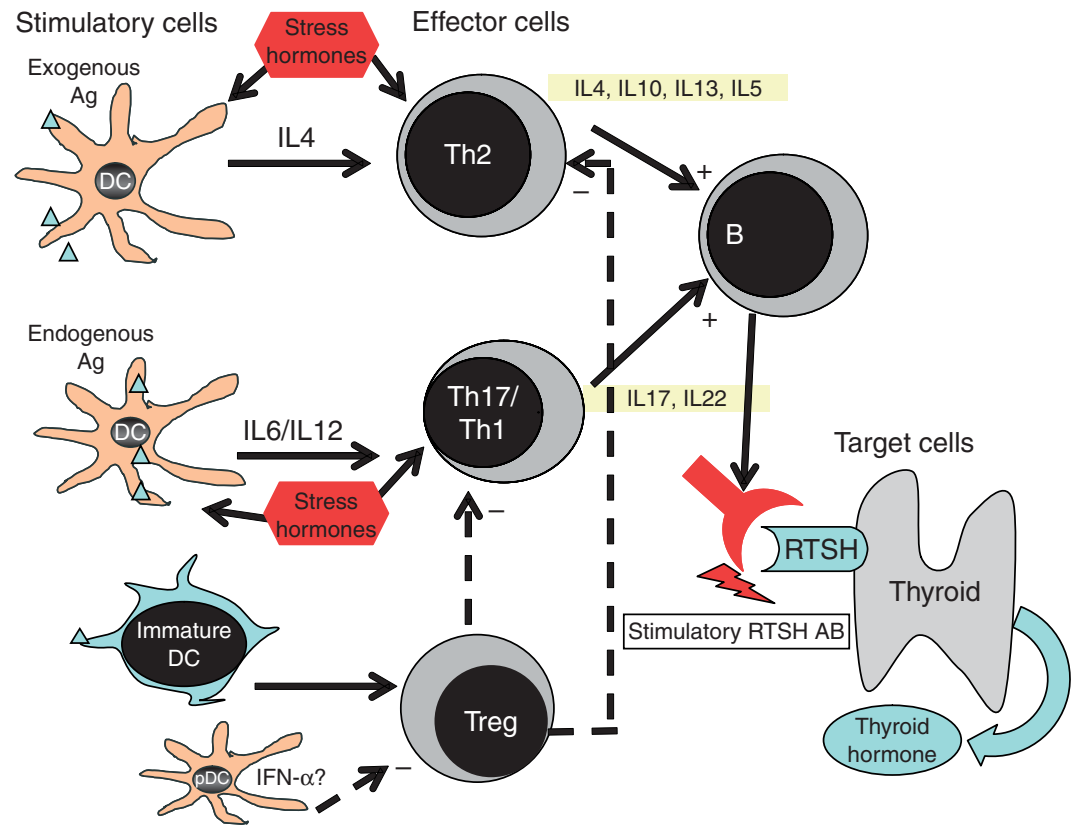

Figure 1 Proposed role of stress hormones in Graves' disease pathophysiology. The major Th cells involved in Graves' disease are Th2. Recently, Th17 has been described both in mice and humans to favor the production of the pathogenic antibody directed against the TSH receptor by $B$ lymphocytes. Stress hormones can induce production of IL4, IL6, and IL12 by DC. Stress hormones can induce direct stimulation of Th2, and Th17 or Th1. Immature DCs induce apoptosis in Treg cells. Then Treg cells could not act like regulators of Th2 and Th17 effector cells that are supposed to both be pathogenic in Graves' disease: i) Treg cells have been found to be low in patients with untreated Graves' disease and inversely correlated to serum concentration of TSH receptor antibodies; and ii) intrathyroid steroid treatment could restore their function.
One hypothesis is that activated pDC, then highly producing IFN- $\alpha$, could together with high level of thyroid hormones favor impaired capacities of Treg and, thus, facilitate the production of autoantibodies against TSH receptor. Altogether, these data put Treg in a key role in Graves' disease pathophysiology. Moreover, Weetman (32) hypothesized that the improvement of Graves' disease in pregnancy, as well as the post partum susceptibility to Graves' disease, might be linked in part to the Treg overproduction by the pregnant mother.

\section{Hormones}

Glucocorticoids Many cells of the immune system such as $\mathrm{T}$ and $\mathrm{B}$ cells, neutrophils, monocytes, and macrophages express glucocorticoid receptors. At pharmacological doses, glucocorticoids are immunosuppressive by impairing leukocyte migration, decreasing antigen presentation, and expression of MHC class II antigens, inhibiting the proliferation and differentiation of lymphocytes, and decreasing the effect of cytokines. But at physiological concentrations, as observed during stress, glucocorticoids secreted by the adrenal gland during the activation of the hypothalamic-pituitaryadrenal axis have immunomodulatory roles. They suppress the production of IL12 by APCs and decrease the expression of IL12 receptors on T cells. In contrast, they increase the production of IL4 and IL10 by Th2 cells. Thus, there is an imbalance in favor of Th2 cells leading to the development of humoral immunity (23). During stress, the adrenal production of DHEA decreases. DHEA directs the immunity toward a Th1 response. Therefore, the decrease in DHEA can also promote a Th2-type immunity (23). However, as is well known, serum levels of DHEA decrease with age. If DHEA decrease had to play a role in facilitating Graves' disease, the peak of incidence for Graves' disease would have been in the elderly, and not in the young adult, as it is.

Catecholamines Catecholamines have a similar effect (23). Receptors to catecholamines (adrenaline and noradrenaline) are expressed by $\mathrm{T}$ and $\mathrm{B}$ cells, natural killer cells, monocytes, and macrophages. They suppress the production of IL12 by APCs, inhibit the production of tumor necrosis factor- $\alpha$, and potentiate the production of IFN- $\gamma$ by APCs. $\beta-2$ adrenergic receptors are expressed only on Th1 cells. The agonists of these receptors inhibit the production of IFN- $\gamma$ by Th1 cells. In mice, preexposition of DC to epinephrine induces an overmaturation phenotype. Moreover, epinephrine-lipopolysaccharide-stimulated DC produce IL12 and IL23 that favor IL4 and IL17 production by effector T cells (33). This is a Th2/Th17 environment known to be appropriate for the occurrence of autoimmune diseases.

These effects of catecholamines are consistent with an imbalance in favor of Th2 cells. Interestingly, a case of relapse of Graves' disease has been reported at the onset of a pheochromocytoma (34). However, if the favoring role was exerted by excess catecholamines, then there would have been many more reports of Graves' disease elicited/precipitated by pheochromocytoma.

Glucocorticoid and catecholamine stimulation of the immune system are not the only mechanisms that link stress to autoimmunity. Depression and stress are characterized by a production of proinflammatory cytokines, among them IL6, a DC and macrophage-produced 
cytokine. Serum levels of IL6 are elevated in stress (35). This could directly cause the Th1/Th17/Treg imbalance implicated in autoimmune diseases (36). In parallel, nuclear factor $-\kappa \mathrm{B}(\mathrm{NF}-\kappa \mathrm{B})$ is rapidly produced after stress, and stress induces NF- $\kappa$ B signaling in mononuclear cells $(37,38)$. The oxidative stress could also be involved in long-term production of proinflammatory cytokines (39). As these cytokines influence regulation mechanisms, this could influence Treg stimulation and function and, thus, have an effect on Graves' disease development.

Sex hormones Stress inhibits the production of estrogens. The corticotropin-releasing hormone inhibits the GnRH secretion (probably via glucocorticoids). Glucocorticoids inhibit the secretion of GnRH and decrease the production of sex hormones and their action at target tissues. Estrogens increase (while androgens decrease) the hypothalamic-pituitary-adrenal axis response to stress. Women activate this axis during stress more than men and this may explain the higher incidence of autoimmune diseases in females. Pregnancy and post partum are interesting conditions to consider in this regard. During pregnancy, there is an increase in the production of glucocorticoids, estrogens, and progesterone. There is also a decrease of proinflammatory cytokines (IL2, IFN- $\gamma$, and IL17) and an increase of type 2 cytokines (IL4), as well as a Treg overproduction. This may prevent the immune rejection of the fetoplacental unit (40). It may also explain the remission of some autoimmune diseases (e.g. rheumatoid arthritis, multiple sclerosis, type 1 diabetes, and Hashimoto's thyroiditis) and aggravation of type 2 autoimmune diseases (e.g. lupus glomerulonephritis) during pregnancy. In the post partum period, hormone levels normalize and the level of Treg decreases.

The sudden termination of the suppressive environment in pregnancy leads to a modification that could favor autoimmune thyroiditis. These changes are evoking the autoimmune phenomena described in the immune reconstitution syndrome, for example observed in human immunodeficiency virus infection $(41,42$, $43,44)$. These immune changes may explain the occurrence of post partum thyroiditis, basically, an attenuated form of Hashimoto's thyroiditis, which is much more common than the occurrence of Graves' disease in the post partum period $(45,46)$. It is possible that such changes can occur at the end of a stress, explaining the occurrence of Hashimoto's thyroiditis after Graves' disease in the same patient $(47,48)$.

Thyroid hormones Does thyroid function affect the immune response? This is a relevant question since thyroxine $\left(\mathrm{T}_{4}\right)$ and triiodothyronine $\left(\mathrm{T}_{3}\right)$ receptors are ubiquitously present. While in experimental hypothyroidism there is a decrease in humoral immunity, the immune status in hyperthyroidism is not clearly defined. What is the effect of stress on the hypothalamic-pituitary-thyroid axis? TSH secretion is suppressed during stress through the activation of the hypothalamic-pituitary-adrenal axis. Glucocorticoids decrease the secretion of TSH. Furthermore, stress decreases the conversion of $\mathrm{T}_{4}$ to $\mathrm{T}_{3}$. Conversely, thyroid hormones potentiate the effects of glucocorticoids and catecholamines. Therefore, there is a 'cross-talk' between the two axes, and a disruption resulting from an excessive secretion of thyroid hormones during thyrotoxicosis can lead to vicious circles between thyroid homeostasis and immune response (8).

\section{Stress and clinical expression of Graves' disease}

A recent study has evaluated the degree of stress, the intensity of symptoms (hyperthyroid symptom scale (HSS) score), and the biological status $\left(\mathrm{T}_{4}, \mathrm{~T}_{3}\right.$, and thyrotropin-binding inhibitory immunoglobulins (TBIIs) serum levels) in 263 consecutive patients (age 32-53 years) with a first episode of Graves' disease. There was an association between the degree of stress and the HSS score. A positive correlation was present between the biological status $\left(\mathrm{T}_{4}\right.$ and $\mathrm{T}_{3}$ serum levels) and the HSS score. Older age was associated with less severe hyperthyroidism, both clinically (lower HSS score) and biochemically (lower free $\mathrm{T}_{3}$, free $\mathrm{T}_{4}$, and TBII serum levels). But this study did not reveal any effect of stress on biological parameters. In other words, stress can directly influence the clinical expression of the disease (49). However, one may argue that a statistically significant association between severity of stress and severity of biochemical hyperthyroidism is not necessarily expected because two major determinants of the latter are thyroid size and concentrations of TSH receptor-stimulating autoantibodies.

\section{Stress and relapse of Graves' disease}

A study on patients treated with radioactive iodine has shown that patients who had a previous history of stress were affected earlier by hypothyroidism when compared with patients with no history of stress (12 vs 36 months). This may be due to the potentiation of radioactive iodine effect by stress-induced autoimmunity (50). Two studies have shown that the occurrence of stress after the start of antithyroid drug therapy delays the onset of a euthyroid state (51). There are some interesting data supporting the beneficial effect of benzodiazepines on the treatment outcome after antithyroid drugs. A study has shown a decrease in the relapse rate of Graves' disease in patients treated with benzodiazepine compared with untreated patients (29 vs 74\%) (52). A recent publication has also reported the case of a young woman with Graves' disease treated with antithyroid drug in whom repeated exacerbations of hyperthyroidism were triggered by 
stress. Further exacerbations were avoided by starting benzodiazepine treatment soon after she experienced stressful events (53).

\section{Conclusion}

More studies are needed for a more robust conclusion. The data in favor of an effect of stress remain circumstantial and not evidence-based, and mostly suggested by expert opinion and theoretical effect of stress on immune mechanism. Nevertheless, the role of stress in the pathophysiology of Graves' disease is suggested by several clinical observations and by recent advances in immunology and better understanding of autoimmune diseases.

This issue is important as if stress has a causal role in Graves' disease, its management would be an important part of the treatment of Graves' disease. Limited work activity, rest, avoidance of daily stressors, stress management, and use of benzodiazepine should be recommended. It is also interesting to consider that the use of propranolol, which decreases the conversion of $\mathrm{T}_{4}$ to $\mathrm{T}_{3}$ with the subsequent reduction in heart rate, can also be beneficial by affecting mood. As far as benzodiazepine use is concerned, we have to admit that there are no interventional data supporting such recommendations and clarifying, for instance, which patients should receive benzodiazepine, or which molecule, dose, duration of treatment, etc. Also, the effect of rest, although largely recommended in clinical practice, is not supported by interventional data.

\section{Declaration of interest}

The authors declare that there is no conflict of interest that could be perceived as prejudicing the impartiality of the review reported.

\section{Funding}

This review did not receive any specific grant from any funding agency in the public, commercial or not-for-profit sector.

\section{References}

1 Nabipour I, Burger A, Moharreri MR \& Azizi F. Avicenna, the first to describe thyroid-related orbitopathy. Thyroid 200919 7-8. (doi:10.1089/thy.2008.0299)

2 Graves RJ. Newly observed affection of the thyroid gland in females. London Medical and Surgical Journal 18357 516-517.

3 von Basedow CA. Exophthalmos durch hypertrophie des zellgewebes in der augenhöhle. Wochenschrift Für Die Gesammte Heilkunde 18406 197-204.

4 Parry CH. Collected works, vol 1, pp 478-480, Ed Underwood. London, 1825.

5 Sawin CT. Theories of causation of Graves' disease. A historical perspective. Endocrinology and Metabolism Clinics of North America 199827 63-72. (doi:10.1016/S0889-8529(05)70298-X)

6 Endo K, Kasagi K, Konishi J, Ikekubo K, Okuno T, Takeda Y, Mori T \& Torizuka K. Detection and properties of TSH-binding inhibitor immunoglobulins in patients with Graves' disease and Hashimoto's thyroiditis. Journal of Clinical Endocrinology and Metabolism 197846 734-739. (doi:10.1210/jcem-46-5-734)

$7 \mathrm{Lidz}$ T. Emotional factors in the etiology of hyperthyroidism. The report of a preliminary survey. Psychosomatic Medicine 1949 $112-8$.

8 Bagnasco M, Bossert I \& Pesce G. Stress and autoimmune thyroid diseases. Neuroimmunomodulation $2006 \quad 13$ 309-317. (doi:10.1159/000104859)

9 Winsa B, Karlsson A, Bergstrom R, Adami HO, Gamstedt A, Jansson R, Adamson U \& Dahlberg PA. Stressful life events and Graves' disease. Lancet 1991338 1475-1479. (doi:10.1016/ 0140-6736(91)92298-G)

10 Sonino N, Girelli ME, Boscaro M, Fallo F, Busnardo B \& Fava GA. Life events in the pathogenesis of Graves' disease, A controlled study. Acta Endocrinologica 1993128 293-296.

11 Kung AW. Life events, daily stresses and coping in patients with Graves' disease. Clinical Endocrinology 199542 303-308. (doi:10.1111/j.1365-2265.1995.tb01879.x)

12 Radosavljević VR, Janković SM \& Marinković JM. Stressful life events in the pathogenesis of Graves' disease. European Journal of Endocrinology 1996134 699-701. (doi:10.1530/eje.0.1340699)

13 Yoshiuchi K, Kumano H, Nomura S, Yoshimura H, Ito K, Kanaji Y, Ohashi Y, Kuboki T \& Suematsu H. Stressful life events and smoking were associated with Graves' disease in women, but not in men. Psychosomatic Medicine 199860 182-185.

14 Martin-du Pan RC. Triggering role of emotional stress and childbirth. Unexpected occurrence of Graves' disease compared to 96 cases of Hashimoto thyroiditis and 97 cases of thyroid nodules. Annales d'Endocrinologie 199859 107-112.

15 Matos-Santos A, Nobre EL, Costa JGE, Nogueira PJ, Macedo A, Galvão-Teles A \& De Castro JJ. Relationship between the number and impact of stressful life events and the onset of Graves' disease and toxic nodular goitre. Clinical Endocrinology 200155 15-19. (doi:10.1046/j.1365-2265.2001.01332.x)

16 Paunkovic N, Paunkovic J, Pavlovic O \& Paunovic Z. The significant increase in incidence of Graves' disease in eastern Serbia during the civil war in the former Yugoslavia (1992 to 1995). Thyroid 19988 37-41. (doi:10.1089/thy.1998.8.37)

17 Tomer Y. Genetic susceptibility to autoimmune thyroid disease: past, present, and future. Thyroid 201020 715-725. (doi:10.1089/thy.2010.1644)

18 Guarneri F \& Benvenga S. Environmental factors and genetic background that interact to cause autoimmune thyroid disease. Current Opinion in Endocrinology, Diabetes, and Obesity $2007 \mathbf{1 4}$ 398-409. (doi:10.1097/MED.0b013e3282ef1c48)

19 Caturegli P, Kimura H, Rocchi R \& Rose NR. Autoimmune thyroid diseases. Current Opinion in Rheumatology 200719 44-48. (doi:10.1097/BOR.0b013e3280113d1a)

20 Brix TH, Kyvik KO, Christensen K \& Hegedüs L. Evidence for a major role of heredity in Graves' disease: a population-based study of two Danish twin cohorts. Journal of Clinical Endocrinology and Metabolism 200186 930-934. (doi:10.1210/jc.86.2.930)

21 Hemminki K, Li X, Sundquist J \& Sundquist K. The epidemiology of Graves' disease: evidence of a genetic and an environmental contribution. Journal of Autoimmunity 201034 J307-J313. (doi:10.1016/j.jaut.2009.11.019)

22 Weetman AP. Autoimmune thyroid disease: propagation and progression. European Journal of Endocrinology 2003148 1-9. (doi:10.1530/eje.0.1480001)

23 Tsatsoulis A. The role of stress in the clinical expression of thyroid autoimmunity. Annals of the New York Academy of Sciences 2006 1088 382-395. (doi:10.1196/annals.1366.015)

24 Nanba T, Watanabe M, Inoue N \& Iwatani Y. Increases of the Th1/Th2 cell ratio in severe Hashimoto's disease and in the proportion of Th17 cells in intractable Graves' disease. Thyroid 200919 495-501. (doi:10.1089/thy.2008.0423)

25 Guo J, Pichurin P, Nagayama Y, Rapoport B \& McLachlan SM. Insight into antibody responses induced by plasmid or adenoviral 
vectors encoding thyroid peroxidase, a major thyroid autoantigen. Clinical and Experimental Immunology $2003 \quad 132$ 408-415. (doi:10.1046/j.1365-2249.2003.02170.x)

26 Horie I, Abiru N, Saitoh O, Ichikawa T, Iwakura Y, Eguchi K \& Nagayama Y. Distinct role of $\mathrm{T}$ helper type 17 immune response for Graves' hyperthyroidism in mice with different genetic backgrounds. Autoimmunity 201144 159-165. (doi:10.3109/ 08916931003777247)

27 Horie I, Abiru N, Nagayama Y, Kuriya G, Saitoh O, Ichikawa T, Iwakura Y \& Eguchi K. T helper type 17 immune response plays an indispensable role for development of iodine-induced autoimmune thyroiditis in nonobese diabetic- $\mathrm{H} 2{ }^{\mathrm{h} 4}$ mice. Endocrinology 2009150 5135-5142. (doi:10.1210/en.2009-0434)

28 Figueroa-Vega N, Alfonso-Pérez M, Benedicto I, Sánchez-Madrid F, González-Amaro R \& Marazuela M. Increased circulating proinflammatory cytokines and Th17 lymphocytes in Hashimoto's thyroiditis. Journal of Clinical Endocrinology and Metabolism 2010 95 953-962. (doi:10.1210/jc.2009-1719)

29 Nagayama Y, Horie I, Saitoh O, Nakahara M \& Abiru N. $\mathrm{CD} 4{ }^{+} \mathrm{CD} 25^{+}$naturally occurring regulatory $\mathrm{T}$ cells and not lymphopenia play a role in the pathogenesis of iodide-induced autoimmune thyroiditis in NOD-H2h4 mice. Journal of Autoimmunity 200729 195-202. (doi:10.1016/j.jaut.2007.07.008)

$30 \mathrm{Hu}$ Y, Tian W, Zhang LL, Liu H, Yin GP, He BS \& Mao XM. Function of regulatory T-cells improved by dexamethasone in Graves' disease. European Journal of Endocrinology 2012166 641-646. (doi:10.1530/EJE-11-0879)

31 Mao C, Wang S, Xiao Y, Xu J, Jiang Q, Jin M, Jiang X, Guo H, Ning $G$ \& Zhang Y. Impairment of regulatory capacity of $\mathrm{CD} 4{ }^{+} \mathrm{CD} 25^{+}$regulatory $\mathrm{T}$ cells mediated by dendritic cell polarization and hyperthyroidism in Graves' disease. Journal of Immunology $2011 \mathbf{1 8 6}$ 4734-4743. (doi:10.4049/jimmunol. 0904135)

32 Weetman AP. Immunity, thyroid function and pregnancy: molecular mechanisms. Nature Reviews. Endocrinology 20106 311-318. (doi:10.1038/nrendo.2010.46)

33 Kim BJ \& Jones HP. Epinephrine-primed murine bone marrowderived dendritic cells facilitate production of IL-17A and IL-4 but not IFN- $\gamma$ by CD $4^{+}$T cells. Brain, Behavior, and Immunity 201024 1126-1136. (doi:10.1016/j.bbi.2010.05.003)

34 Abe M, Mori K, Nagai K \& Ito S. Relapse of Graves' disease in a patient with pheochromocytoma. Endocrine Journal $2003 \mathbf{5 0}$ 767-770. (doi:10.1507/endocrj.50.767)

35 Vgontzas AN, Zoumakis E, Bixler EO, Lin HM, Follett H, Kales A \& Chrousos GP. Adverse effects of modest sleep restriction on sleepiness, performance, and inflammatory cytokines. Journal of Clinical Endocrinology and Metabolism $2004892119-2126$. (doi:10.1210/jc.2003-031562)

36 Boissier MC, Assier E, Falgarone G \& Bessis N. Shifting the imbalance from Th1/Th2 to Th17/treg: the changing rheumatoid arthritis paradigm. Joint, Bone, Spine $2008 \mathbf{7 5} 373-375$. (doi:10.1016/j.jbspin.2008.04.005)

37 Brydon L, Edwards S, Jia H, Mohamed-Ali V, Zachary I, Martin JF \& Steptoe A. Psychological stress activates interleukin- $1 \beta$ gene expression in human mononuclear cells. Brain, Behavior, and Immunity 200519 540-546. (doi:10.1016/j.bbi.2004.12.003)

38 Miller GE, Chen E, Sze J, Marin T, Arevalo JMG, Doll R, Ma R \& Cole SW. A functional genomic fingerprint of chronic stress in humans: blunted glucocorticoid and increased NF- $\kappa$ B signaling. Biological Psychiatry 200864 266-272. (doi:10.1016/j.biopsych. 2008.03.017)
39 Kiecolt-Glaser JK, Preacher KJ, MacCallum RC, Atkinson C, Malarkey WB \& Glaser R. Chronic stress and age-related increases in the proinflammatory cytokine IL-6. PNAS 2003 100 9090-9095. (doi:10.1073/pnas.1531903100)

40 Saito S, Nakashima A, Shima T \& Ito M. Th1/Th2/Th17 and regulatory T-cell paradigm in pregnancy. American Journal of Reproductive Immunology 201063 601-610. (doi:10.1111/j. 1600-0897.2010.00852.x)

41 Rasul S, Delapenha R, Farhat F, Gajjala J \& Zahra SM. Graves' disease as a manifestation of immune reconstitution in HIV-infected individuals after initiation of highly active antiretroviral therapy. AIDS Research and Treatment, 2011. (doi:10. $1155 / 2011 / 743597)$

42 Weetman A. Immune reconstitution syndrome and the thyroid. Best Practice \& Research. Clinical Endocrinology \& Metabolism 2009 23 693-702. (doi:10.1016/j.beem.2009.07.003)

43 Crum NF, Ganesan A, Johns ST \& Wallace MR. Graves' disease: an increasingly recognized immune reconstitution syndrome. AIDS 200620 466-469. (doi:10.1097/01.aids.0000196173.42680.5f)

44 Chen F, Day SL, Metcalfe RA, Sethi G, Kapembwa MS, Brook MG, Churchill D, de Ruiter A, Robinson S, Lacey CJ et al. Characteristics of autoimmune thyroid disease occurring as a late complication of immune reconstitution in patients with advanced human immunodeficiency virus (HIV) disease. Medicine 2005 84 98-106. (doi:10.1097/01.md.0000159082.45703.90)

45 Gaberščček S \& Zaletel K. Thyroid physiology and autoimmunity in pregnancy and after delivery. Expert Review of Clinical Immunology 20117 697-707. (doi:10.1586/eci.11.42)

46 Roti E \& Uberti E. Post-partum thyroiditis - a clinical update. European Journal of Endocrinology 2002146 275-279. (doi:10. 1530/eje.0.1460275)

47 Umar H, Muallima N, Adam JMF \& Sanusi H. Hashimoto's thyroiditis following Graves' disease. Acta Medica Indonesiana 2010 42 31-35.

48 McLachlan SM, Nagayama Y, Pichurin PN, Mizutori Y, Chen CR, Misharin A, Aliesky HA \& Rapoport B. The link between Graves' disease and Hashimoto's thyroiditis: a role for regulatory T cells. Endocrinology 2007148 5724-5733. (doi:10.1210/en. 2007-1024)

49 Vos XG, Smit N, Endert E, Brosschot JF, Tijssen JGP \& Wiersinga WM. Age and stress as determinants of the severity of hyperthyroidism caused by Graves' disease in newly diagnosed patients. European Journal of Endocrinology 2009160 193-199. (doi:10.1530/EJE-08-0573)

50 Stewart T, Rochon J, Lenfestey R \& Wise P. Correlation of stress with outcome of radioiodine therapy for Graves' disease. Journal of Nuclear Medicine 198526 592-599.

51 Yoshiuchi K, Kumano H, Nomura S, Yoshimura H, Ito K, Kanaji Y, Kuboki T \& Suematsu H. Psychosocial factors influencing the short-term outcome of antithyroid drug therapy in Graves' disease. Psychosomatic Medicine 1998 60 592-596.

52 Benvenga S. Benzodiazepine and remission of Graves' disease. Thyroid 19966 659-660. (doi:10.1089/thy.1996.6.659)

53 Vita R, Lapa D, Vita G, Trimarchi F \& Benvenga S. A patient with stress-related onset and exacerbations of Graves disease. Nature Clinical Practice. Endocrinology \& Metabolism 20095 55-61. (doi:10.1038/ncpendmet1006)

Received 20 June 2012

Revised version received 12 September 2012

Accepted 1 October 2012 